\title{
2006 Donald E. Cummings Memorial Award Lecture Industrial Hygiene: The Founders, The Pioneers, and The Next Generation
}

\author{
Steven P. Levine, PhD, ClH, AlHA Fellow, and Emeritus Professor
}

\begin{abstract}
The Donald E. Cummings Memorial Award was established in 1943 as a tribute to Donald E. Cummings, AIHA's third president. The award is given for outstanding contributions to the knowledge and practice of the profession of industrial hygiene.
\end{abstract}

This paper is about the Founders of industrial hygiene, the Pioneers who followed them, and the Next Generation of industrial hygienists. It highlights the development of industrial hygiene and how that development did not necessarily follow a master plan but has nonetheless been constructive and manageable.

There has been and continues to be much conversation and debate about the status of our profession (from within our profession), most of which seems to center on what is wrong and how we are threatened. But as long as we focus on the core definition of what it means to be an industrial hygienist, change has been and will continue to be beneficial in the long run.

To help us understand why our profession should feel confident about the future, I offer the reader a tour of some of the people who have guided and influenced the direction of the profession in the past, recent past, and present, and those who are likely to be guiding us into the future. The Founders planted the seeds that "became" industrial hygiene. The Pioneers "grew the trees and harvested some low-hanging fruit" (and some "not so low-hanging fruit"). (The Founders and Pioneers are in their sixties, seventies, and eighties, and some have passed on.) The Next Generation is planting "new types of crops and becoming better farmers."

Two rules must be understood when reading this paper:

(1) Most of the luminaries in an imagined industrial hygiene "Hall of Fame" are neither listed nor discussed because of limitations of space and time. Whether or not a person is included in this article does not represent a judgment about a person's contribution to the profession, so please forgive errors of omission.

(2) I will not list each person's elected or appointed office in professional societies nor, in most cases, will I list the awards that they have received.

\section{THE FOUNDERS}

$\mathrm{T}$ he story begins with Alice Hamilton:

"Thirty-two years ago, in 1910, I went as a pioneer into a new, unexplored field of American medicine, the field of industrial disease.... It was a voyage of exploration that we undertook ... for nobody knew even where we should [start] ... ignorance and indifference was not confined to the medical profession—employers and workers both shared it." (1)

The role of the physician as occupational physician, toxicologist, industrial hygienist, and epidemiologist was the global model used during much of the 20th century. By the latter part of the 20th century, this now-archaic and ineffective model had been abandoned by developed nations but still lived on in the communist and newly post-communist world.

\footnotetext{
"The employers could, if they wished, shut their eyes to the dangers workmen faced, for nobody held them responsible, while workers accepted the risks with fatalistic submissiveness as part of the price one must pay for being poor ... there was no use going to the [government] factory inspectors: they were ignorant and powerless." (1)
}

It is striking to reflect on the accomplishments of Dr. Hamilton. She almost single-handedly created a niche between the plant and the physician - a niche that is now occupied by

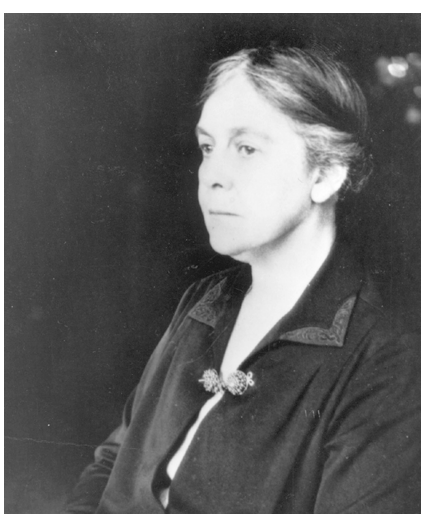


industrial hygienists and occupational physicians. Also, it is easy for readers in the year 2006 to forget that Dr. Hamilton was a woman working in a man's world. This was certainly unimaginably harder to do 100 years ago than it is today. In recognition of Dr. Hamilton's tireless and inspiring work, the Cummings award was bestowed on her in 1948.

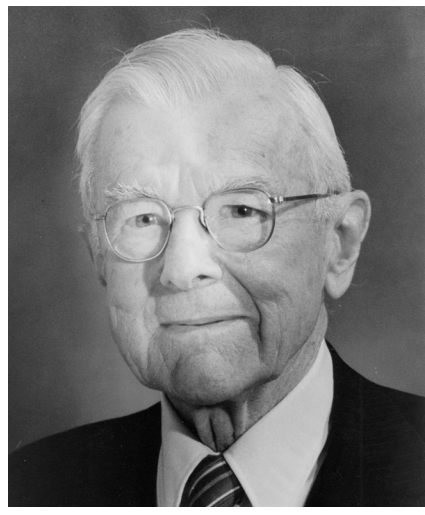

The next of the Founders I will briefly mention is Warren Cook. One of his accomplishments was the clear articulation of the role of the industrial hygienist in the casualty insurance business:

"It assists industry in economic control of health hazards and, for the wage earner it strives to obtain improved environmental conditions." (2)

Another of his accomplishments was the publication in the Journal of Industrial Medicine and Surgery in November $1945 .^{(3)}$ It included a list that would become the underpinning of the threshold limit value (TLV) list of that time and, to an extent that would have both delighted and dismayed him, remains today the values of all too many of the modern OSHA permissible exposure limits (PELs). In recognition of his contributions to the field of industrial hygiene Warren Cook received the 1953 Cummings Award. He clearly articulated the need for quantitative occupational exposure limits (OELs) in his Cummings paper:

\footnotetext{
"In discussing ... the advantages of quantitative over the qualitative... if we want to buy a rug for a room, we stand a better chance not to be disappointed if we go to the shop... to tell the salesman that the rug is for a room four yards by five yards rather than merely to say: Well it is really quite a nice big room.... The emphasis on the quantitative may seem too evident to discuss but it has been a long time being accepted."(4)
}

When reading the above quotation, please remember that he was speaking in 1953. In 1987, when Professor Cook was 87 years old, he published the landmark work Occupational Exposure Limits-Worldwide (an AIHA publication). Professor Cook was also an academic scholar. He was one of the founding faculty of the industrial hygiene program at the University of Michigan.

The Founders of industrial hygiene created the profession by integrating related scientific disciplines using a public health model. They began professional societies to foster collaboration. During the late 20th century, toward the end of the "period of the Founders," there were many well-respected leaders of our profession. Two who are especially worthy of mention are Morton Corn, the first industrial hygienist to lead OSHA and who worked to craft a role for industrial hygiene in government, and Harry Ettinger, who indefatigably toiled to draft and implement the PEL Update Project of 1989. ${ }^{(5)}$ In addition, they must be acknowledged for their work in mentoring scores of young IHs. Both men worked throughout their careers to define where the profession is or should be headed. ${ }^{(6)}$ Ettinger advocated that industrial hygienists should be industrial hygienists and not dilute their skills and knowledge by trying to be experts in allied fields. ${ }^{(7)}$ Professor Corn (then a professor at Johns Hopkins University) and Mr. Ettinger were the recipients of the Cummings Awards in 1986 and in 2003, respectively.

\section{THE PIONEERS}

$\mathrm{T}$ he Pioneers of industrial hygiene followed the Founder's generation. I will arbitrarily put industrial hygienists who are in or almost in their sixties in the Pioneers' generation (Pioneers are those who started to contribute in the 1970-1980 period, and will continue to contribute into the early years of the 21st century.) My list of the Pioneers starts with Professor Patricia Brogan of Wayne State University. She fashioned and implemented a strategy and program in noise control while employed at Ford Motor Company. This program, which defined the corporate OEL for noise as $85 \mathrm{db}$, used the strategy of "Buy It Quiet." Ford Motor Company, as a major purchaser of industrial machinery, used its leverage with suppliers to make them design and sell quiet machinery if they wanted to keep Ford as their customer. This underscored the power and importance of the customer-supplier interaction. For this, and other accomplishments, Professor Brogan received the Alice Hamilton Award from the AIHA in 2003.

The Pioneers made chemical exposure assessment a legitimate and central issue of inquiry and by doing so made the possibility of obtaining quantitative information a reality for all industrial hygienists. Eugene Kennedy is one such Pioneer: He spent his career at the NIOSH Alice Hamilton Laboratory developing methods of sampling and analysis for trace levels of organic compounds in air. He contributed to the NIOSH Manual of Analytical Methods, ${ }^{(8)}$ which is the most important publication in the world on this subject.

Professor Roy Rando of Tulane University is another Pioneer. In one of his projects, he worked on the development and validation of a denuder to differentiate vapor-phase from aerosol diisocyanates. Professor Rando faced the problem that during the late 20th and early 21st centuries, NIOSH funding for research fell and became increasingly focused on direct support of projects that were primarily or entirely occupational epidemiological projects. Therefore, for Professor Rando, funding from the International Isocyanate Institute was critical. If we allow government funding for research in exposure 
assessment to wither, then a major accomplishment of the Pioneer generation will be lost.

Yet another industrial hygiene Pioneer worthy of mention is Jim D'Arcy of General Motors Corp. who just completed a 1-year rotation through the position of chief scientist for General Motors' global operations. He was the organizer, convener, and co-chair of two national conferences on metal removal (also called metalworking) fluids. In the past 5 years his efforts have been focused on the issue of field evaluation for auto production processes of aerosol monitors, including those capable of monitoring particles in the sub-micrometer (nanometer) size range. This is the first work of its kind. It will lead the way to Next Generation research and practice. D'Arcy's favorite quote is from Dr. Hamilton:

"For me the satisfaction is that things are better now, and I had some part in it."

When they retire, will there be replacements for Kennedy at NIOSH, Rando at Tulane, and D'Arcy at GM? What will the Next Generation do if these and related fields of research and application do not continue?

Once air contaminant assessment methods have been developed, they are used in investigations of the exposure of workers. Perhaps the single most important group of field industrial hygienists in the United States is the group supervised by Dawn Tharr at NIOSH. If you want a team of IHs that performs the most, most varied, high-quality, and well-focused field studies of high-priority industrial hygiene problems: "Who ya gonna call"? Although this started out as a line from the movie Ghost Busters, this quote has pervaded our society with 242,000 references on Google. Nonetheless, the metaphor is aptly applied to Ms. Tharr's Industrial Hygiene Section. This group was and is the single best example of Pioneers who applied IH principles and practices in industrial settings.

Leadership in industrial hygiene research by industry continues to be an important factor in the health of our profession. For example, an appropriate model or guide for sampling strategy and statistics, is the definitive book on the subject by the Pioneers of this field, John Mulhausen of 3M Corporation and Joseph Damiano of Alcoa. Their textbook is the globally accepted guide for this subject. ${ }^{(9)}$

This generation must be recognized as the generation who improved and applied industrial hygiene curricula for undergraduate and graduate education. With the Spanish language quickly becoming the second language of Americans, the needs of the Spanish-speaking population must be recognized. One of the educational programs that has filled that void is the Industrial Hygiene Program at the University of Puerto Rico. They prepare industrial hygienists where the need for Spanish language practitioners exists and serve as a local, regional, national, and international resource for Spanishlanguage information dissemination, continuing education, and consultation services. The program director is Professor Jesus Gonzalez.

Spreading the "western model" of industrial hygiene practice globally has been an accomplishment of the Pioneer generation. One such Pioneer is Professor Roy Buchan of Colorado State University who works to advance global industrial hygiene practice (or occupational hygiene as it is most often referred to outside the United States). As just one example, he worked in Romania to help them convert from a "postcommunist" model of our profession to a functional model that will serve the Romanian economy and workers well when that country becomes a full member of the European Union.

The subject of international industrial hygiene must include Guy Bourgeoisat. He started his career as a laboratory technician with 3M France, and is now the Global IH Manager with L'Oreal Corp. He is also the founder (1991) and president of the Société Française des Hygiénistes du Travail, and a board member of the International Occupational Hygiene Association (IOHA). Guy has implemented modern industrial hygiene methods for French and the world's industries and workers, while at the same time being a leading industrial hygiene educator in France.

Another non-American global Pioneer is Professor Namwon Paik, Emeritus Professor and Dean, School of Public Health, Seoul National University. Prior to the start of the Korean War, Paik's mother had strapped little Namwon to her back and walked in the black of night through a minefield north of Seoul to escape from Pyongyang. Paik has memories of the Korean War - the invasion of the south by the marauding armies from the north. After the war, Paik went to the United States where he was trained as an industrial hygienist. During his stay in the United States, he and Professor Brogan published the first peer-reviewed paper on exposure assessment of and laboratory methods for asbestos. ${ }^{(10)}$ Paik then went back to Republic of Korea (South Korea) where he founded the profession of industrial hygiene. Virtually all of the "secondgeneration" of college-trained industrial hygienists in Korea are his students.

It is evident that world-class contributors to industrial hygiene can come from any country. I have mentioned only two of many such contributors. If we knew the true measure of workers that were protected through these efforts, we might be pleased beyond our wildest dreams. We might also be stunned by the magnitude of the global problems still facing industrial hygienists.

The principles and practices of industrial ventilation have been for some time almost universally known. (The truth of that statement notwithstanding, I have encountered instances of seemingly wanton disregard and/or lack of knowledge of the principles and practices of ventilation on more than one occasion.) The Pioneer in the field of ventilation has been and still is D. Jeff Burton. Jeff has led the way in both the United States and on a global scale. He, more than most, understood, taught and applied the hierarchy of interventions. For his accomplishments he earned the Cummings award in 2004. ${ }^{(11)}$

\section{THE NEXT GENERATION AND VERSATILISTS}

7 he Next Generation of industrial hygienists is leading the profession into the 21 st century. The IH profession will be 
defined for the 21 st century by new leaders who will define and implement new policies, procedures, methods, devices, and regulations. Professions grow and flourish if there are leaders who recognize that a necessary survival skill is the ability to adapt to rapidly changing requirements of the marketplace. One can easily observe that many if not most segments of the marketplace are not static, so why should a person assume that the customers of industrial hygienists will always have the need for the same services requiring an unchanging skill set?

Customers will always require that industrial hygienists have the capability to tackle the important problems of the day. The key to this is lifelong learning, and the ability to systematically apply new knowledge to new problems. The leaders in the field of industrial hygiene must understand the $\mathrm{IH}$ marketplace and thereby understand the skills and knowledge needed to supplement core scientific and mathematical skills. One way to do this is for industrial hygienists to be educated and trained as

- "Versatilists... Building employee versatility and finding employees who already are or are willing to become versatilists will be the new watchword for career planning."(12)

In the past, words commonly used in the industrial hygiene profession were:

- Specialist: Deep skills and narrow scope-expertise that is "recognized by their peers but may be rarely valued by the marketplace."(13)

- Generalist: Broad scope and narrow skills-expertise that enabled them to "respond or act quickly but often without gaining... the confidence of their partners or customers."(12)

But now we must value:

- "Versatilists apply depth of skill to a progressively widening scope of situations, and experiences, gaining new competencies, building relationships and assuming new roles."(12)

Clearly, this applies to the profession of industrial hygiene in the 21 st century. Surprisingly, given the tenor of recent discussions and debates, this was always the case for at least some members of our profession.

\section{THE NEXT GENERATION: OELS AND OTHER UNFINISHED JOBS}

$\mathrm{O}$ ne of the "unfinished jobs" of both the Founders and the Pioneer generations, possibly a result of the intractable nature of the underlying problem and/or cloudy vision of members of both generations, is the problem of occupational exposure limits. A set of unified criteria for OELs is needed. Why did we develop OELs that have diverging criteria such as "financial and technological feasibility" in some OELs and "nearly all workers" in another set of OELs? What does "nearly all workers" mean? What were we thinking when we introduced inefficient/ineffective methodology for developing OELs that are applicable to OSHA? Why do we not have OELs that use appropriate groupings of chemicals to cover more chemicals? How should we approach the issues surrounding OELs for simultaneous multihazard exposures involving presumably additive adverse health effects? What about the need for biologically based OELs for materials that are contaminated with viable organisms (i.e., metal removal fluids)? Why, in our failure to develop and apply new OELs, have we not dealt with the escalating role played by litigation? Exactly what role should litigation play in the development and promulgation of OELs?

But that is not all of the subjects on the list of unfinished jobs that my generation (The Pioneer Generation) is bequeathing to The Next Generation. The list includes: evaluation and control of exposure to "difficult" air contaminants such as ultrafine particles; understanding the impact of a mobile workforce taking with them the cumulative effects of exposures without a system to either track the exposures or understand the cumulative effects; improved linkage between exposure assessment and epidemiology; improved linkage between exposure assessment and medical surveillance; reinvigorating academic and applied IH research; linking OHS aspects of financial and process management; implementation of the U.S. national OHS management standard; international corporate IH management in the environment of a "flat world;"(12) reshaping the structure and role of government for OHS; ergonomics; workplace violence; IH in service industries; global IT systems; global analytical accreditation; and last but not least, replacement and recruiting for the profession.

\section{ESTABLISHED LEADERS OF THE NEXT GENERATION}

Wuture contributions in industrial hygiene will come from The Next Generation of young people. If the Founders "planted the seeds" and the Pioneers "nurtured the seeds and harvested the low-hanging fruit" then the Next Generation is "planting new types of crops and becoming better farmers."

One member of the Next Generation is Mark Puskar. He was the first member of his family to get a college degree, no less a doctorate. Puskar had dual skill sets-industrial hygiene and computer programming, both of which he applied to his doctoral work and his professional career. His doctoral work pioneered the use of an advanced instrumental method "Attenuated total reflectance-Fourier transform infrared spectroscopy (ATR-FTIR)" to identify hazardous waste mixtures. Now instrument manufacturers are selling the next generation of such instruments to the next generation of emergency responders to identify the next generation of important unknown mixtures - the so-called potential chemical/biological warfare agents. Interestingly (and alarmingly) this next generation of instruments ignores the spectral interpretation issues that Puskar addressed in his thesis 20 years ago.

In his professional work at Abbott Laboratories, Puskar supervises the industrial hygiene laboratory. He was also the Founder and first Chair of AIHA Analytical Accreditation 
Board. Now he spends most of his time on the corporate information technology (IT) system.

"We have five large global IT systems [for] managing our EHS risks. I am the system owner of these applications."

So we see that, for the Next Generation, "traditional IH practice" is transcended by $\mathrm{IH}$ practice that includes new major skill and knowledge areas (IT), and we see that the borders of the U.S. are transcended by a global corporate effort.

A second member of the Next Generation is Alan Leibowitz. $\mathrm{He}$ is Director, Environment, Safety, Health and Security for ITT Industries. He manages global (40 countries) aspects of compliance for ITT. He is editor/author of the important book Industrial Hygiene Auditing: A Manual for Practice, AIHA Press (1994). As his "extracurricular activity," Mr. Leibowitz was chair of the AIHA-ANSI Z10 Accredited Standards Committee for the development of a "Safety and Health Management System" standard for the United States. This effort to write an American national standard on occupational health and safety systems was a long, demanding project fraught with land mines placed by conflicting interests and levels of knowledge of the stakeholder groups (primarily industry and labor). We would never have had a successful process leading to this national standard if not for the extraordinary interpersonal skills and situational awareness of Mr. Leibowitz. His quiet, self-effacing manner belies (and perhaps complements) those interpersonal skills.

A third member of the Next Generation is Christopher Strang. Strang started his IH career as a plant industrial hygienist specializing in air monitoring and hazmat response when he worked at AT\&T. He then moved to the corporate IH group at Monsanto, reporting to John Henshaw before Mr. Henshaw went on to become the director of OSHA during the first George W. Bush administration. These were "traditional" IH jobs in "traditional" settings. Then, his next major career step occurred when he moved to the position of director of environment, occupational hygiene (including medical), safety, security, and fire protection at the world's largest integrated nylon manufacturing facility near Pensacola, Florida. Note that this was not a "traditional" IH job, but Strang (now a CIH and a CSP) still considered himself to be an industrial hygienist. He now performed many jobs involving environmental issues such as hazardous waste and water quality. He was also in charge of security, which certainly does not fall under the category of "traditional IH." He has recently moved to a job that is roughly equivalent but is now in the pharmaceutical industry (Brisol Myers-Squibb). In this position he does not have responsibility for either the medical or the security staffs. Now, instead of working with nylon and its precursors, he is working with potent pharmaceutical agents with very low corporate OELs.

The most consistent and applicable descriptor of Strang's career is that he had-he was expected and required by his employer-to engage in lifelong learning. He was, and still is, a "Versatilist." That is why he is successful. In a recent paper, an author commented, "If we broadly expand our scope we compromise our technical excellence and replace it with superficial familiarity." ${ }^{(13)}$ For those for whom that statement is true, failure is inevitable. However, industrial hygienists of The Next Generation will be expected to efficiently and effectively engage in real lifelong learning and to thereby become true versatilists.

While it may be true of some of the Founders and Pioneers that they were (and still are) "traditional industrial hygienists," I believe that more and more of The Next Generation will be expected to be versatilists as a condition of continued employment. I am skeptical of the claim that most of the Pioneers were or are "traditional industrial hygienists." I started my career in industry as an analytical chemist evaluating the efficiency of a wet electrostatic scrubber on a stack at a sulfuric acid sludge recycling plant (Environment). My second assignment was to evaluate existing and develop, validate, and train plant personnel on a new method for sampling and analysis of VCM in workplace air (Industrial Hygiene). My third assignment was to measure near-LEL conditions at a parathion intermediate plant (Safety). All three assignments were while I was in the same job for the same employer. My employer expected my contemporaries and me to learn and perform such tasks as a condition of employment.

My next example of The Next Generation of established IH leaders is Jonathan Rosen. Rosen started the first 17 years of his career as a factory worker and activist prior to attending college and getting his industrial hygiene degree. He is now the director of occupational hygiene and safety at the N.Y. State Public Employee's Federation (PEF) in which job he facilitates 130 PEF joint OHS committees. He says:

\begin{abstract}
"[My] work experience has helped me to be more effective in leading the [union's] H\&S program... My focus has been on workers in the state institutions such as Mental Health, Mental Retardation, Corrections, Youth Detention Facilities, etc.... the biggest hazard is violence from patients, inmates, clients.... I am co-investigator on two NIOSH grants to do intervention studies on violence prevention." (14)
\end{abstract}

Is his job "traditional industrial hygiene"? In the context of The Next Generation, I believe that the answer is and indeed must be "yes!"

Another established leader of The Next Generation is Michael Brandt. Brandt not only has advanced degrees in industrial hygiene, he also has an advanced degree in health care administration. Since his industrial hygiene thesis was on the subject of management methods, ${ }^{(15)}$ it is not surprising that he has gravitated to jobs that utilize his skills and knowledge. At the time of the writing of this paper he was acting chief of staff for operations at Los Alamos National Laboratories. As AIHA Treasurer in 2001-2004, he (with active and effective collaboration from Steven Davis and Peter O'Neil of AIHA staff) both turned AIHA finances around and introduced a zerobased budget program. In the 2005 election, AIHA members voted Brandt back on the Board of Directors. He is an exemplar of the "versatilist archetype" that I expect is and will be the 
norm for many, if not most, industrial hygienists of The Next Generation.

Another of my examples of established leaders of The Next Generation of industrial hygienists is Donna Doganiero. She is the director of the Occupational Health Sciences Department at the U.S. Army Center for Health Promotion and Preventive Medicine. She and her staff have responsibility for ergonomics, ionizing and nonionizing radiation, vectorborne diseases (entomology), medical safety, and health hazard assessment for base and field units worldwide. In all past wars the number of injuries, illnesses, and fatalities from noncombat deaths exceeded those numbers from combat deaths. It is the job of Donna and her staff to reduce those numbers.

Her staff also has had the lead responsibility for worker safety and health protection during nuclear, biological, and chemical (NBC) readiness, incident responses, and cleanups. ${ }^{(16)}$ This is an expanded role for her staff forced on them by the "War on Terror." For each task, she and her staff were forced to acquire and utilize new knowledge and skills- to be versatilists as a condition of employment. How did Doganiero work her way up from a Mine Safety and Health Administration (MSHA) field project officer? She did it by being an effective versatilist.

Established industrial hygiene leaders work for industry, national laboratories, the military, unions, and a very few work for county governments. One of the benchmarks of industrial hygiene within a Public Sector/County government is the program "created"-if not created, then shaped, focused, and improved-by Brian Berke. Berke is the Safety and Health Manager for Employee Safety and Loss Control for Palm Beach County's Risk Management Division. (Admittedly, the tax base of Palm Beach County, Florida, allows the county to perform such functions when many other counties cannot do so or lack the understanding of the value of such a program.) His work includes everything from "A to Z" in industrial hygiene. He is responsible for OHS aspects of: animal control; asbestos remediation; building indoor air quality in a hot, humid climate; construction site safety; emergency response in hurricanes; office ergonomics; public transportation safety and third-party liability both for employees and for the public (many of whom are elderly and infirm); and youth affairs. (This, I understand, is a list that only goes from "A to Y," not from "A to Z." While there is a Palm Beach Zoo, its employees do not fall within Berke's jurisdiction.) Berke has just been elected to his second term as Florida AIHA Local Section President.

Lest the reader think that Berke has abandoned the field of "traditional industrial hygiene" for a Palm Beach "boutique" practice, Berke put in his years as an industrial hygienist working for Pratt and Whitney in Florida where, at an asbestos removal project, the asbestos had become infested with poisonous pigmy rattlesnakes. Understandably, his favorite saying is:

"Any time things are going well you have probably overlooked something." with which he closes his e-mails. He is not a pessimist. In reality, by saying this he indicates that success comes only when all details of a project/program are considered.

One example of a non-American established leader of The Next Generation of industrial hygienists is Professor Dooyong Park. Park is a "second generation" Korean industrial hygienist, the "first generation" being Professor Namwon Paik the "father of Korean IH" at Seoul National University of whom I wrote earlier. Park is now, at age 40, the youngest person to ever be the director of South Korea's NIOSH (the KOSHA Institute). He was propelled into this position as a result of his successful project to review OSHA/NIOSH organizational structures worldwide and to recommend optimal solutions to the South Korean government. What is the optimal structure? The structure could be (but I doubt it), at one extreme, the U.S. structure with OSHA in the Department of Labor and NIOSH buried within the Centers for Disease Control and Prevention. Many of the South Korean governments OELs are ACGIH TLVs that South Korea has adopted. What will Professor Park do about South Korean government OELs? Professor Park is doing "traditional industrial hygiene" albeit at a very high level.

I will finish this category of "Established Leaders" of The Next Generation with comments from the 1999 Kusnetz Award winner, Tom Hethmon, who is vice-president for Environment, Safety and Occupational Health of Rinker Materials Corporation. Hethmon is quoted:

\footnotetext{
"There are many US companies that need IH services, but don't know it. Instead of waiting for them to call us, generalist-IH's (HSE generalist) need to get into those companies as safety or environmental professionals or risk managers and educate management about the need for $\mathrm{IH}$ services: Grow from within!"

"There remains an inadequate supply of IH's across the globe and a growing global economy with multinational companies operating in many countries, fewer and fewer of which are American. If you want to expand the horizons of the profession, you will have to get on a plane or boat. Think global."

"Historically, we have done a poor job of educating the general public about our profession. If the public knew about us and what we do on behalf of their communities and working men and women, there would be greater direct and indirect demand for industrial hygiene. The public may create demands for our services in ways we have not even considered."(17)
}

These quotes represent positive, constructive thinking that is a far cry from the writings of those who either warn against the devolution and degradation of "traditional industrial hygiene" and/or from those who warn of the decrease in demand for the services provided by industrial hygienists.

\section{THE NEXT GENERATION-EMERGING TALENT}

$\mathrm{T}$ he AIHA Leadership Workshop and the Future Leaders Institute is helping to identify, train and nurture 
young leaders. One of The Next Generation who was one of the developers of the Future Leaders Institute is Cynthia Ostrowski. The AIHA is eager and excited to continue to offer this program for years to come. Ostrowski, who has had experience working in the workers' compensation insurance industry, is now an IH consultant who has been a long-standing member of the very important Michigan Governor's State Health and Safety Compliance and Appeals Board. She was previously a board member and then president of the Michigan Industrial Hygiene Society. She is now a board member of the AIHA.

A second of my examples of the emerging talent of The Next Generation of industrial hygienists is Shelley WheelingPark. Wheeling-Park has, early in her career, become the director of Environmental, Health \& Safety, plus the Regional Safety Officer of Kaiser Permanente in Honolulu. Her job is to develop, implement, and manage all EHS programs for the Hawaii Region, which includes: $4500+$ employees, a 250-bed hospital, and 25 clinics and peripheral facilities. She attended AIHA's Future Leaders Institute and AIHA's Leadership Workshop in her role as the AIHA's Hawaii Local Section President. She sees "real value in those leadership training programs."

A third emerging talent is Trina Redford. She is a U.S. Navy industrial hygienist where she performs the duties of supporting fleet and on-shore IH service; develops and administers IH training; evaluates fleet workplaces; provides $\mathrm{IH}$ lab support; and provides career counseling. She is a member of the AIHA Minority SIG; the Epidemiology, Social Concerns, and Emerging Issues committees, and she is an active volunteer for many community charities. She attended the AIHA's Future Leaders Institute.

Another person who is clearly an emerging talent in The Next Generation is Perry Logan. Logan is a doctoral student in industrial hygiene at the University of Minnesota; the manager of industrial hygiene (with responsibility for global oversight and support) for the 3M Specialty Division where, in 1999, he won a $3 \mathrm{M}$ corporate award for performing IH monitoring using Fourier Transform Infra-Red (FTIR) methods. In the year in which he was chair of the AIHA Gas and Vapor Detection Systems Committee that committee won an award for Outstanding Committee. For these and other accomplishments before the age of 40, Logan won the 2006 Kusnetz Award. He attended the AIHA's Future Leaders Institute.

My final example of an "emerging talent" is Laurie Scott. She works for Philips Semiconductor where she established (as a team member) an Environment, Health (industrial hygiene), and Safety (EHS) department with programs, policies, and procedures. She is EHS program and services owner for "everything you can think of" in that department. She reviews, inspects, and approves new manufacturing equipment purchases, facility layouts, installations, and engineering controls for compliance with government regulations and standards, and is also Laser Safety and Radiation Safety Officer. She attended AIHA's Future Leaders Institute. Clearly, at a young age, she is a "versatilist."

\section{CONCLUSION}

$\mathrm{M}$ y message about the "generations" of the industrial hygiene profession and the profiles of individual industrial hygienists give me reason to predict that the profession of industrial hygiene will continue, adapt, and flourish in the $21 \mathrm{st}$ century. My conclusions are:

- Industrial hygiene's leaders during the 20th century defined the goals and objectives of that century.

- The strength of the industrial hygiene profession in the $21 \mathrm{st}$ century is and will be ensured by the high quality of people who have taken the leadership reins.

- These new leaders have been and will be redefining the goals and objectives of industrial hygiene to meet ever-changing challenges.

- Industrial hygienists of the 21 st century will be required by the marketplace to be "versatilists" and will do so by engaging in effective lifelong learning.

- The recruiting and training of such young industrial hygienists will ensure the continued strong stewardship and leadership of the profession.

- There remain many complex technical and political issues that are likely to have a direct impact on the perceived and real future role of industrial hygiene.

I am confident that The Next Generation is committed to recognizing these challenges. With the aid and counsel of the Founders and Pioneers, these challenges will give The Next Generation another chance for the profession to show its best characteristics.

\section{ACKNOWLEDGMENTS}

I owe all my success in my career (and my life) to my lovely, supportive wife, Barbara. In addition, I owe special thanks to Tom Hethmon for many helpful suggestions that resulted in key improvements in concepts, wording, and structure of both my Cummings presentation and this paper. I also would like to thank Harry Ettinger for nominating me for this award, and both Howard Cohen and my wife for timely and useful reviews of this manuscript.

\section{DISCLAIMER}

T have made every effort to check the accuracy of my 1 facts. However, if I have made mistakes in the biographical descriptions of persons or their accomplishments, I offer my heartfelt apologies. Any such error was inadvertent.

\section{SOURCES AND NOTES}

1. A. Hamilton. Exploring the Dangerous Trades. Boston: Little, Brown and Company, 1943

2. W.A. Cook. A Unique American Institution. Am. Ind. Hyg. Assoc. Quart. 14(2):89-97 (June 1953).

3. His paper on OELs actually appeared in the AIHA Journal. During the first 5 years of the AIHA Journal (1941-1946) it was published as a quarterly 
supplement in the Industrial Journal of Medicine, Volume 11, pp. 936946 (1945). Warren Cook was the editor of the journal during those years. The first full printing of the AIHA Journal as a stand-alone publication was as Volume 6 in 1946.

4. W.A. Cook. (1953) op. cit.

5. H.J. Ettinger. Henry Smyth Award Lecture-Occupational Exposure Limits: Do We Need Them? Who Is Responsible? How Do We Get Them? J. Occup. Environ. Hyg. D25-D30 (2005).

6. That subject having been covered by Corn and Ettinger in, among other places, the AIH Diplomate of March 2001.

7. H. Ettinger. 2003 Donald E. Cummings Award Lecture-Industrial Hygienists: Who We Are, Priorities, Goals, Limitations. Am. Ind. Hyg. Assoc. J. 64:724-78 (2003).

8. "NIOSH Manual of Analytical Methods" in the "NIOSH Pocket Guide to Chemical Hazards" DHHS (NIOSH) \# 2005-151 (CD).

9. J.R. Mulhausen and J. Damiano. A Strategy for Assessing and Managing Occupational Exposures, Second Edition. Fairfax, Va.: AIHA Press, 1998.
10. N. Paik, R.J. Walcott, and P.A. Brogan: Worker exposure to asbestos during removal of sprayed material and renovation activity in building containing sprayed material. Am. Ind. Hyg. Assoc. J. 44(6):428-432 (1983).

11. D. Jeff Burton. 2004 Donald E. Cummings Award Lecture: Industrial Hygiene in Decline-What Can We Do? J. Occup. Environ. Hyg. D148 D152 (2004).

12. T.L. Friedman. The World Is Flat-A Brief History of the Twenty-First Century. New York: Farrar, Straus and Giroux Inc., 2005.

13. H. Ettinger. (2003) op. cit.

14. J. Rosen to S. Levine, personal communications. March 2006

15. Activity-Based Cost Management (ABCM) Applied to an ES\&H Department and Program. The University of Michigan, School of Public Health, 1997.

16. The NBC Battlebook: USACHPPM Guide 244-Readiness Through Health. May 2000, and later editions.

17. T. Hethmon to S. Levine, personal communications. Spring 2006. 